\title{
Implementing of Reading Strategies in the Academic Process as the Productive Way of Foreign Text Understanding
}

\author{
Svetlana I. Pozdeeva 1 \\ Liubov A. Sobinova ${ }^{2}$ \\ ${ }^{1}$ Professor, Doctor of Education, Tomsk State Pedagogical University, 60, Kievskaya Street \\ Tomsk 634061, Russia, svetapozd@mail.ru \\ 2 Senior instructor, National Research Tomsk Polytechnic University, 30 Lenin Avenue \\ Tomsk, 634050, Russia; sla_19.82@mail.ru
}

Doi:10.5901/mjss.2015.v6n6s4p390

\section{Abstract}

The authors of the paper put the relevant issue associated with a perception of foreign texts presented in English for pupils and students at schools and universities. It is approved that children's and youth's deformation of common cultural reading skills demands new working ways with foreign material. Based on "learning strategy" and "reading strategy" definitions the authors suggest the algorithm to be studied and applied in the academic process at schools and universities as the main way to understand authentic texts. Types and subtypes of reading strategies are worked out according to student reading activity at schools and universities in Russia. Moreover, the authors illustrate vivid handouts that can be used by teachers of foreign languages. The conclusion about the development of reading literacy and competence shaping is made at the end of the paper.

Keywords: reading strategy; reading types; development; referential; informative, algorithm.

\section{Background}

At the present time the method of teaching to read is an issue about the choice of effective strategies for working with an informative text. The informative text is represented as a nonfiction text which contains a complete section of information (scientific, educational or technical) and concentrated on the available sources (a tutorial, an electronic tutorial, a guide book, an encyclopedia, a scientific edition). Thus, the problem of an effective reading strategy choice is relevant for reading both in native (Russian) and foreign (English) languages. This fact is related to a deformation of common cultural reading skills in the modern society, especially it is observed among children and youth. The problem of reading literacy and reading competence of pupil and student works with informative texts nowadays is extremely sharp. In this case, the following difficulties, connecting to the reader's self-activity with regard to native (Russian) and foreign (English) languages appear.

Firstly, imitative reading: students do not want to show cognitive efforts (to strain) at independent reading; their activity is very superficial, mechanical and formal. It becomes obvious that the traditional printed books take a back due to the widespread electronic and audio books, as well as the negative impact of the Internet explains the destruction of reading skills at schools and universities. Moreover, linguists consider that the active use of text slide presentations at school lessons and university lectures play a certain negative role in the development of reading skills. Students accustom to perceive, effortlessly a lightweight unit of information allocated and structured by a teacher. Here, they do not want to exert themselves during independent reading of informative texts because they have to make extracting and structuring of new information.

Secondly, students have a gap in possessing different kinds of reading strategies (revision, skim, selective and detailed reading) and algorithms. They are not able to pick out the basic information from a text, to fix it, to interpret it, to formulate their own attitude about the presented material. In other words, students and pupils suffer from "the fear of a text"; they do not know how to organize the semantic reading: to form the aim of reading independently, to choose the right kind of reading according to its aim and realize it on the basis of a productive strategy or method. Speaking by words of Russian great poet Alexander S. Pushkin, reading ceases to be the best learning. Under those circumstances, scientists (linguists, psychologists, methodologists) and teachers are currently looking for efficient strategies of the independent reading activity organization. 


\section{Literature Overview}

Strategies in their broadest meaning - are the clear program of actions consciously used to control leaning with the aim of improving and getting the particular goals that are interested for an individual. The term strategy, in relation to reading is studied by different Russian and foreign authors. For example, Margarita Mosina means a strategy as "a reader's path that makes the necessary direction and order, excluding randomness" (Mosina, 2009, p. 13). According to her, possessing reading strategies in foreign language implies:

1) Goal setting taking into account the features of an educational situation and personal objectives;

2) The same way of working with changing materials (academic, technical, scientific);

3) A reader owns a set of learning actions that are implemented to understand the text and use its information;

4) If a learner possesses a certain reading strategy, he can teach it another incompetent reader.

In this case, it is appropriate to consider the term "reading strategy" as "learning strategy" because it has a broader meaning.

As for other researchers, there is no common opinion about the term "strategy" and required set of them in the process of learning to read foreign texts.

Thus, the first researches in this area belong to J. Rubin, who highlighted learning strategies as methods and techniques used by learners in acquiring knowledge. In his works learning strategies were divided into two groups: strategies connected with the language learning directly or indirectly. The first group was presented with the following strategies: rectification, monitoring, remembering, guessing, deductive reasoning; the second one included speech practice.

Concerning reading strategies as learning strategies the algorithm of actions comes to the fore, from $\mathrm{O}$. YA. Gojman and T. M. Nadeina points of view. Reading algorithm is a sequence of mental and practical actions, allowing streamlining and organizing the reading process (Gojhman, Nadeina, 2007).

J. Rubin's opinion is not accepted in the field of science as a unique one. Specifically, H. D. Brown suggests that there are some fundamental strategies which learners use both to master a foreign language and actualize verbal communication (Brown, 1980). Moreover, the author denotes the difficulty of distinguishing one strategy from another while the process of foreign language learning. This idea is supported by other scientists. For example, R. Ellis defines learning strategies as a compensatory way to specify inaccuracies of code knowledge (Ellis, 1993, p. 165). He claims that learning and communicative strategies are interchangeable and closely connected to each other, successfully recompensing the lack of the linguistic competence.

The researcher, A. Cohen is also close to this opinion. He asserts that strategies used by learners unite academic and training strategies (Cohen, 1994). Together they represent chosen by students' actions and direct to increase the success of foreign language acquisition. The communicative reading strategy is possible to consider as a strategy aimed to understand all the levels of the text (main idea, topic, subtopic and problem) and reflect its material. In other words, if reading strategies are focused on extracting main and useful information from the text, and therefore, interpreting the text (what can be understood, can be interpreted).

E. Tarone supposes that learning and communicative strategies chase different purposes in foreign language education. According to him, learning strategies motivate students to study foreign languages, but communicative, in turn, encourage to use it communication (Tarone, 1989, p. 419). However, further she recognizes that in practice there is not an exact way to identify learners' motivation, so, "the boundary between learning and communicative strategies is not clear" (Tarone, 1989, p. 290).

J. O'Malley and his colleagues in their researches used the strategy definition given by J. Rigney. According to him learning strategies are "actions and steps which contribute acquisition, storage, recovering and operation of information"(Malley, 1990, p. 18). In his researches they are classified into three groups: metacognitive (knowledge about learning), cognitive (specific to each type of educational activity) and social (interactive).

This concept was given its further development in R. Oxford's researches who separated all learning strategies into six groups. The classification has: remembering strategies (related to students' remembering of the language material); cognitive (connected with directly to what students study); compensatory (help learners to recompense low linguistic knowledge); metacognitive (refer to how students cope with an academic material); affective (reflect emotions and feelings during the education) and social (involve interaction). However, according to the author's point of view "there is not an agreement regarding to the learning strategy, the number of its existence, the way of its highlighting, defining and distinguishing on categories, and finally if there is any objective possibility or it will appear in the future to create a real scientific valid hierarchy of strategies. (Oxford, 2003, p. 17). The following classification of learning strategies got a great popularity among researchers in the field of foreign language teaching, as the most complete and perfect in 
methodological studies.

In all diversity of learning strategies, it seems appropriate to allocate the R. Oxford's classification due to its accurate reflection of learning activities on "Professional foreign language" in a technical university. And it allows to mobilize resources of students' knowledge in their professional area by means of foreign language, balancing between different disciplines, reflecting strong and hiding weak points of learners.

\section{Reading Types Classification}

The basis of reading strategy is an idea - never read for nothing: we always follow the particular aim and get the corresponding result. It means that we must not teach reading in general, but introduce a variety of types in reading. The aim-result is exactly the key goal of the reading division into types and subtypes. In this research, the authors support the classification of T. Serova that is presented by two main reading types - referential and informative.

Referential reading is aimed at extracting the topic of an educational text only, and addressed to referents of the text, a theme line, in other words to names of subjects, events and processes. It is carried out in situations of correlating the textual material with the reality in the process of a fast and efficient thematic reworking. The key words in the textual topic serve as supports for vertical reading. Referential reading has three subtypes: orienting-referential, searchingreferential and generalizing-referential.

Orienting-referential reading occurs in conditions when the overall orientation in the material is obligatory or when there is a purpose to establish which professional areas of knowledge, problems in the text are. The objective of this subtype is the orientation in main textual referents, relating the total content of an educational text to the reality.

Searching-referential reading is carried when there is a sharp necessity in finding absolutely definite information. The main objectives in this case are a referent target search, a topic distinguishing and an educational text content.

Generalizing-referential reading takes place in situations of the specific educational text reading when there is an importance to identify for yourself and others the volume of a subject content, to emphasize and specify words-referents. The objectives of this subtype are not only to associate an educational text content with a subjective reality, but an obligatory explicitation, a specification of a text subject plan, a selection of main and subordinate referents from the common set. This subtype is realized in contexts of reading familiar texts, making an abstract, informative reviewing of specific literature in a foreign language.

The second type of the classification is informative reading. It is realized due to information that is necessary to reveal the conceptual idea of an educational text. That is why this type reading is directed to perception and understanding not only the referents, but the idea that was mentioned about them in the text. Informative reading as well as referential one has three subtypes: assessment and informative, assign and informative and creating and informative reading.

Assessment and informative reading is held by learners when there is a necessity to assess the textual material from the usefulness, relevance and adequacy of its volume and quality point of view. The assessment criterion serves as an individual experience, the volume of students' knowledge (their thesaurus). The objectives of this subtype is specification and qualification of topics in line with predicate hierarchy, the text meaning distinction and its concept, comparing them with one's experience. The product of this activity is conclusions, thoughts about the value of the particular educational text within the professional or academic activity.

Assign and informative reading supposes an assumption of the original information as it is given by the author in a text by means of making different notes (notices, outlines plans, synopsis and translation).

The objectives of this subtype are predicate hierarchy's selection, distinction and fixation of socially developed meaning and gaining a personal experience. The product of the following subtype is an illation about the effect of an educational text.

Creating and informative reading assumes a creative approach and using of the received information in order to create an individual expression (coinciding or not with an author's opinion) in oral or written form. Thus, it might well be used to exchange information between group representatives, its distribution to others by way of articulated thoughts, conclusions and assessment of posed by the author information.

Speaking about professional and technical literature that is characterized by a standard descriptive data and structured composition that allow students performing a quick information search, decreasing reading time and creating an information adequate and complete picture of what is involved in a text. Based on the experience of foreign language teaching in a technical university, the authors of the paper constitute the basic types of reading classification: orientingreferential, assign and informative, creating and informative readings.

As the result of it,reading activity is determined as a complex speech activity due to the academic needs of a 
reader and an informative search, assumption, further knowledge and experience sharing in a manner of professional and personal communication.

\section{Reading Strategy Algorithms}

Reading algorithms allow ordering the work process with an informative text depending on a goal a reader pursues. In this case there are both integral and differential reading algorithms spark the interest (Gojhman, Nadeina, 2007) that are well used for teaching to read at schools and universities (applied in mother tongue as well as in foreign language).

Integral reading algorithm spreads on the whole text in general and permits to make the process of reading through the particular steps to extract all useful information out of it. It helps to protect a reader's brain from being overinformed (useless repetitions, verbosity, intertextual duplication and minor information). After the first (introductory) reading of a text, its rereading happens (studying): reading and filling the worksheet. For example, see Appendix A.

As the result of integral algorithm application all useful information is packed into three main blocks:

1) Publisher's imprint (author and title);

2) Main content and factual data;

3) Assessment and benefit of received knowledge.

Paying attention to the note made in a worksheet, a very special way of reading material fixing must be admitted by which information selection, fixation and transformation occurs.

Differential reading algorithm is aimed at the main information extraction and written compression of a text due to key words' isolating, semantic numbers' building and textual dominants' identification. Completing all the steps of the given algorithm is accompanied by making a three column table.

The first step is devoted to finding of key words in a text. Performing it necessary to take into account the word named the topic of the text is not a key one. There could also be sentences without key words at all (if it duplicates information of the previous one or involves extra details). Choosing key words or phrases is crucial to consider a sentence length. Key word are underlined and noted in a table while maintaining their grammatical forms.

The second step is making semantic numbers applying key words. A semantic number is a shortened phrase (from the text or constructed by a reader based on the material) with a key word: as many groups of key words written out, as many semantic numbers will be. The syntactic link is also very important between semantic numbers (words -"bridges": pronouns, synonyms, conjunctions). After filling the second column learners read the resulted text and make a conclusion about its size. If it is necessary, they may add some corrections to make it holistic and coherent.

The third step is a dominant construction. A dominant is one complete and detailed sentence (not a phrase or a title) expressing the main idea of a text or a paragraph. If to read all the dominants the maximum degree of the text compression is obtained. The example of it is illustrated in Appendix B.

The simultaneous use of both algorithms is the most efficient variant of this strategy: initially integral reading algorithm is performed and then differential one could be realized on the example of the same text. As a result of this activity not only retention of a textual content but also written fixation of information happens. Besides that, the ability to convey the content of a text in short and written form considering different degrees of compression could well be regarded as a basic skill of semantic reading both in native and foreign languages.

\section{Conclusion}

The problem of an effective teaching to read in foreign language can be decided due to using of productive strategies and algorithms. It is important for a teacher to understand that the key to success is not just the ability to read as a technical skill associated with the understanding of words, sentences and paragraphs, but also teaching students to train methods of working with a text. The importance of such a work is equally crucial both in teaching of foreign (English) and native (Russian) languages. The authors' experience convince the fact that if the reader doesn't have reading strategies in relation to the texts written in native language, he will have difficulties in foreign language reading too.

However, there is an inverse correlation: if a student masters the foreign reading strategies he puts them to work with information in the mother tongue. This can be confirmed by the following example. The long known types of reading in the methodology of foreign language "migrated" to the methodology of teaching the mother tongue and received the status of universal educational actions in new Standards of primary and secondary education. Generally speaking, reading becomes a universal (meta-subject) action which is the key to successful educational and personal development of students. 


\section{References}

Brown, H. D. (1980). Principles of Language Learning and Teaching: 4 ed. N.Y.: Pearson, 40.

Cohen, A. (1994). Cognitive and motivational aspects of action: selected rev. papers. Great Britain: W. Hacker, 73.

Ellis, R. (1993). Second Language Acquisition Research: How does it help teachers? ELT Journal, 47 (1), 3-11.

Gojhman, O. YA., Nadeina, T. M. (2007). Rechevaya kommunikaciya [Speech communication]. Moscow: INFRA, 272, 118-124.

Kozharskaya, E. et al. (2008). Guide to Science Student's Book. Macmillan Publishers Ltd, 61-63.

Mosina, M. A. (2009). Realizaciya interaktivnogo podhoda v kompleksnom obuchenii professional'no-orientirovannoj inoyazychnoj rechevoj deyatel'nosti: [Interactive approach realization in the competence-based education of professionally oriented foreign activity]. Seriya 1/2 (62), Problemy obrazovaniya, nauki i kul'tury [Series 1/2 (62) Problems of education, science and culture]. Izvestiya Ural'skogo gosudarstvennogo universitet [The Bulletin of Ural State University], 128-134.

O'Malley, J. M. (1990). Learning Strategies in Second Language Acquisition. Cambridge: Cambridge University Press, 42.

Oxford, R. L. (2003). Learning styles and strategies. Oxford: GALA, 20-25.

Rigney, J. M. (1978). Learning Strategies: A Theoretical Perspective Learning Strategies. New York: Academic, 20-25.

Rubin, J. (1989). How learner strategies can inform language teaching. Hong Kong: Institute of Language in Education, 108.

Serova, T. S. (2009). Obuchenie gibkomu inoyazychnomu professional'no-orientirovannomu chteniyu v usloviyah delovoj mezhkul'turnoj kommunikacii [Training of flexible and professionally oriented foreign language reading in business and intercultural communication condtions]. Perm': Perm Press, 35-39.

Tarone, E. (1989). Focus on the Language Learner. Oxford: Oxford University Press, 18-22.

\section{Appendix A. The Example of Integral Algorithm}

Electromagnetism is everywhere. It is a field that exists throughout space. When particles are electrically charged, the electromagnetic field exerts a force on them. These particles then move and exert a force on the electromagnetic field. By generating these fields when and where we want them and by controlling these forces we have electricity. This gives us the power we use in the modern world. All our TVs, phones, street lights and cars depend on electromagnetism. So what is electromagnetism? Actually, it is two things, but they are so closely connected that it is convenient for us to think of them as one, as two sides of the same coin. There are two types of field: electric and magnetic. Electrically-charged particles result in an electric field, static electricity. When there is a conductor, a material which will allow an electric field to pass through it, then we can create an electric current. In our homes, the conductors are the wires that run through our house to the light bulbs or the TV. A magnetic field results from the motion of an electric current and is used to generate the electricity we use. In the 19th century, James Clerk Maxwell, the Scottish physicist, produced the equations that proved the two forces acted as one. One effect of this was for physicists all over the world to hurry back to their libraries and laboratories to rewrite the theories on the motion of objects. Maxwell's equations showed that what physicists had believed for centuries was in fact not correct. It was not until Einstein, in the 20 th century, that the theory of motion was put right - at least for now. How do we know the two things are one? Well, sailors had known for centuries that lightning affected the magnetic compasses on their ships. No one, however, made the connection between lightning and electricity until Benjamin Franklin, the American politician and scientist, flew a kite in a thunderstorm to attract the lightning. In other parts of the world, physicists were experimenting with magnets and electricity. Most passed a current across a magnetic needle and watched it move. The Frenchman, Andre Marie Ampere eventually applied mathematics to electromagnetism. It is from his work that we have our modern understanding of electromagnetism. One piece of the jigsaw remained. No one had discovered a way of generating electricity. True, there were batteries, Alessandro Volta invented the Voltaic pile in 1800, but it was of limited use. Certainly no battery could provide enough electrical power to operate a machine. For that the world would have to wait for Michael Faraday to find a way of creating an electrical current, when and where it was needed.

(Macmillan Press "Guide to Science" Student's Book, 2008)

Useful information from the text

1. Publisher's imprint (title, author, source): Electromagnetism, Guide to Science, Elena Kozharskaya.

2. Main Content (topic, idea, problem)

Topic: Electromagnetism is everywhere. It is a field throughout space.

Idea: This gives us the power we use in the modern world. All our TVs, phones, street lights and cars depend on electromagnetism.

Problem: So what is electromagnetism? It is exerted by electrically charged particles and includes two types of fields: electric (static electricity) and magnetic (motion of electrically charged particles). By generating these fields we have electricity.

3. Facts (names, numbers, data): In the 19th century, James Clerk Maxwell, the Scottish physicist, produced the equations that proved the two forces acted as one. Maxwell's equations showed that what physicists had believed for centuries was in fact not correct. Benjamin Franklin, the American politician and scientist, flew a kite in a thunderstorm to attract the lightning to show the connection between lightning and electricity. The Frenchman, Andre Marie Ampere eventually applied mathematics to electromagnetism. Alessandro Volta invented the Voltaic pile in 1800, but it was of limited use. Michael Faraday found a way of creating an electrical current, when and where it was needed.

4. Text assessment:

New information: No one had discovered a way of generating electricity. For that the world would have to wait for Michael Faraday.

Interesting information: Sailors had known for centuries that lightning affected the magnetic compasses on their ships. No one, however, made the connection between lightning and electricity.

5. Practical application: Applied knowledge in physics, mathematics and history.

\section{Appendix B. The example of Differential Algorithm}

The example of the text

A shark is perfectly adapted for attacks, and thus survival. This predator has a specific dental apparatus. All vertebrates have teeth fixed roots in the jaws, 
but a shark has like a razor teeth held in the skin of the gums in an amount of from 4 to 6 (some species have about 20) rows. Continuing to grow, shark teeth come forward and fall; replaced by rows of back teeth. It was possible to calculate that a tiger shark in 10 years is able to grow, use and lose 24,000 teeth.

\begin{tabular}{|l|l|l|}
\hline Key words & Semantic numbers & Dominants \\
\hline $\begin{array}{l}\text { for attack, dental apparatus, like a razor, } \\
\text { in the skin of the gums, rows of back } \\
\text { teeth, in } 10 \text { years }-24,000 \text { teeth }\end{array}$ & $\begin{array}{l}\text { A shark is adapted for attacks. Its dental apparatus serves this. Like a razor } \\
\text { teeth of a shark are placed in the skin of the gums making many rows. Rows of } \\
\text { back teeth replace the fell teeth. In 10 years it can change about 24,000 teeth }\end{array}$ & $\begin{array}{l}\text { A shark's dental } \\
\text { apparatus is adapted } \\
\text { for attacks }\end{array}$ \\
\hline
\end{tabular}

